\title{
Pierre Bourdieu e Raymond Williams
}

Correspondência, encontro e referências cruzadas

\author{
Luiz Carlos Jackson* \\ https://orcid.org/0000-0002-6269-6096 \\ Ugo Rivetti* \\ https://orcid.org/0000-0003-3368-7219
}

\begin{abstract}
Acabei de chegar de um segundo colóquio em Paris: algo peculiar está acontecendo lá. Um grupo de estudiosos de esquerda, mais novos do que nós, mas não tão novos, estão tentando entrar em contato com a tradição inglesa do trabalho histórico-cultural, como um contraponto tanto ao estruturalismo althusseriano como ao ecletismo americano da moda. Você provavelmente sabe tudo sobre isso: mas o homem com o qual eu acho que nós devemos manter contato é Pierre Bourdieu, do Centre de Sociologie Européenne da Maison des Sciences de l'Homme.
\end{abstract} Trecho de cartão-postal sem data de E. P. Thompson a Raymond Williams².

A breve e concentrada correspondência entre Raymond Williams (1921-1988) e Pierre Bourdieu (1930-2002) constitui prova material, entre outras que menciona-

* Universidade de São Paulo, São Paulo, Brasil.

1. Agradecemos ao Richard Burton Archives (Swansea University) e à Jéròme Bourdieu por nos autorizarem a reproduzir neste artigo, respectivamente, trechos de cartas enviadas por Edward Thompson a Raymond Williams e por Pierre Bourdieu a Raymond Williams. Agradecemos ainda Alejandro Blanco, Daniel G. Williams, Dimitri Pinheiro da Silva, Dmitri Cerboncini Fernandes, Felipe Maia Guimarães da Silva, Fernando Antonio Pinheiro Filho, Katrina Legg, Maria Alice Rezende de Carvalho, Max Gimenes, Sergio Miceli.

2. No original em inglês: "Just back from a second colloque in Paris: something peculiar is happening there. A group of scholars of the left, younger than us but not very young, are trying to make contact with the English tradition of "cultural" historical work, as a counter to either Althusserian structuralism or trendy American eclecticism. You probably know all about this: but the man whom I think we should keep contact with is Pierre Bourdieu at the Centre de Sociologie Européenne at the Maison des Sciences de l'Homme" (Richard Burton Archives - Swansea University. Referência: wwe/2/1/16/365). Esse cartão foi redigido, provavelmente, em 1975, já que o texto de Thompson na Actes de la Recherche en Sciences Sociales é de junho de 1976. Esse dado também sugere que, possivelmente, Thompson tenha intermediado a ida de Williams a Paris em 1976. 
remos a seguir, da existência de relações concretas, de mão dupla, entre os autores galês e francês ${ }^{3}$, muito sugestivas para se pensar o desenvolvimento da sociologia da cultura europeia (mas não apenas) na segunda metade do século $\mathrm{xx}$, processo no qual ambos foram protagonistas.

O objetivo principal deste texto é recensear os contatos concretos que eles mantiveram ${ }^{4}$. O primeiro consiste em duas citações de trechos de livros de Williams por Bourdieu no artigo "Campo intelectual e projeto criador" (Bourdieu, [1966] 1968). O segundo foi a ida de Williams a Paris para participar do "Seminário de Sociologia da Cultura e dos Modos de Dominação”, realizado na École Normale Supérieure em dezembro de 1976 (Chamboredon, 1977, pp. 30-31), do qual resultou a publicação de um texto de Williams na Actes de la Recherche en Sciences Sociales (ARSS). O terceiro contato foi a própria correspondência, poucas cartas concentradas em 1976 e 1977. Por fim, o quarto se deu por meio de um texto crítico de Williams de 1980, escrito em parceria com Nicholas Garnham (Garnham e Williams, 1980), sobre a obra de Bourdieu, em seguida à publicação de $A$ distinção na França. Além desses pontos de contato principais, houve pequenas menções de lado a lado em outros textos.

Esses quatro contatos organizam nosso artigo nos seguintes itens: "Citações", "Encontro", "Correspondência” e "Análise". Os demais contatos que conhecemos serão abordados no interior desses itens e consistem em citações e comentários breves. Em trabalhos de Williams, há citações a Bourdieu em A política e as letras (1979)5 e em Cultura (1980) $)^{6}$ Em livros de Bourdieu, há uma menção a Williams em As regras da

3. Embora seja possível estabelecer aproximações (e diferenças) teóricas entre os autores (como o fizeram com resultados instigantes Jones, 2006, e Passiani, 2009), não é esse o movimento que realizaremos neste texto, que explora pontos de contato propriamente ditos, como citações, resenhas, correspondência e encontros.

4. A sequência de contatos que organiza este texto baseia-se nos episódios que conhecemos. Eventualmente, algum outro pode ter ocorrido, e um rastreamento mais exaustivo poderia incluir outros registros. De qualquer forma, é muito provável que os pontos de contato que analisaremos a seguir tenham sido os mais representativos das relações estabelecidas entre os dois autores.

5. No interior do capítulo "Marxismo e literatura" de A politica e as letras, ao refutar a pretensão de cientificidade de certas análises conservadoras sobre o sistema educacional, Williams se apoia em Bourdieu no seguinte comentário: "Um bom exemplo nas ciências sociais é o reexame, realizado por Bourdieu e seus colegas, dos dados estatísticos sobre os quais foram construídas certas teorias educacionais sobre a igualdade de oportunidades na França”" (Williams, 2013, p. 333, grifos nossos), que demonstraria o caráter enviesado das análises conservadoras.

6. Nesse livro, Williams faz uma referência muito pontual a $A$ reprodução (Bourdieu, 1970): “Assim, algum conceito de reprodução é necessário, se é que devemos ter algum tipo de sociologia crítica da educação ou da tradição, por exemplo. É característico dos sistemas educacionais pretenderem estar transmitindo 'conhecimento' ou 'cultura' em sentido absoluto, universalmente derivado, embora seja óbvio que sistemas diversos, em épocas diversas e em países diversos, transmitem versões seletivas radicalmente diversas de conhecimento e de cultura. Além disso, é certo, como mostraram Bourdieu (1977) e outros, que há relações fundamentais e necessárias entre essa versão seletiva e as relações sociais predominantes em vigor" (Williams, 1992, pp. 183-184, grifos nossos). 
arte ([1992] 2001) e um breve comentário sobre O campo e a cidade ([1973] 1990) em Meditações pascalianas (1997), registros que comentaremos adiante.

De volta à correspondência, tendo como referência as cartas enviadas por Bourdieu a Williams, presumimos que o contato epistolar entre eles se deu principalmente na segunda metade dos anos 1970. As três cartas disponíveis no Richard Burton Archives da Swansea University (País de Gales) são datadas de 22 de dezembro de 1976, 7 de setembro de 1977 e 8 de abril de 1987. Entre estas, a última seria a menos importante, por consistir em uma carta padronizada, endereçada a diversos interlocutores, visando à formação de um grupo de colaboradores para o projeto de um jornal europeu de resenhas.

Conforme consta na "Cronologia de vida e obra" de Bourdieu elaborada por Sergio Miceli (2005), em 1989 foi lançada a "revista trimestral Liber, Revue Européenne des Livres, encartada como suplemento em diversos jornais europeus, em suas respectivas línguas, entre outubro de 1989 e junho de 1991" (Miceli, 2005, pp. 139-40). Segundo o mesmo autor, essa revista se tornaria, em 1994, a Revue Internationale des Livres, publicada até 1998. Williams não contribuiria com essas publicações, já que morreu em 1988, um ano antes do lançamento da primeira revista.

Já as duas missivas anteriores são mais relevantes, porque pessoais. A primeira delas teria sido enviada por Bourdieu pouco depois da ida de Williams a Paris e se concentra em possibilidades de intercâmbio entre eles. A segunda, além de prosseguir nessa negociação, manifesta o que seria, do ponto de vista de Bourdieu, o núcleo da relação estabelecida entre ambos, descrito como um "acordo miraculoso".

\section{Citações}

Salvo engano, o primeiro ponto de contato entre os dois autores encontra-se em duas citaçôes de passagens de Cultura e sociedade (Williams, 1958) e The long revolution (Williams, 1961) no conhecido texto "Campo intelectual e projeto criador"', no qual, segundo Louis Pinto (2000, p. 69), Bourdieu teria apresentado um "primeiro programa de análises" de sua sociologia da literatura, centrada na noção de "campo".

Esse programa, segundo Pinto, incluiria, além de "Campo intelectual e projeto criador" (1968), os textos "O mercado dos bens simbólicos" (1970) e "Campo do poder, campo intelectual e habitus de classe" (1971). Os três textos foram publica-

\footnotetext{
7. Embora as citações de Williams sejam centrais na construção do argumento de Bourdieu, o livro mais citado nesse texto é $O$ gosto literário ([1923]1950), do crítico alemão Levin Schücking.

8. A diferença de idade entre os dois explica, em alguma medida, o fato de a obra de Williams ter sido iniciada mais ou menos dez anos antes do que a de Bourdieu, o que condicionaria o conhecimento anterior dos textos do primeiro pelo segundo.
} 
dos no Brasil pouco tempo depois do que na França. "Campo intelectual e projeto criador" foi publicado pela editora Zahar, por indicação de Moacir Palmeira, em Problemas do estruturalismo (1968), livro que traduziu um número da revista Les Temps Modernes e foi o primeiro texto de Bourdieu editado no Brasil. O texto foi muito importante na primeira fase da recepção do sociólogo francês no país (Bortoluci, Jackson e Pinheiro Filho, 2015). Os outros dois foram publicados na coletânea A economia das trocas simbólicas (1974), organizada por Sergio Miceli.

A primeira referência a Williams em "Campo intelectual e projeto criador" ocorre no início do texto, no interior do movimento analítico de reconstituição histórica do processo de autonomização do campo literário, que teria como um período decisivo, no caso inglês, o romantismo, entre o final do século XVIII e o começo do XIX:

\begin{abstract}
Segundo Raymond Williams, “a mudança radical em matéria de ideias sobre a arte, o artista e seu lugar na sociedade" que (com as duas gerações de artistas românticos: Blake, Wordsworth, Coleridge e Southey de um lado; Byron, Shelley e Keats de outro) coincide na Inglaterra com a revolução industrial apresenta cinco características fundamentais: "primeiro, a natureza da relação entre o escritor e seus leitores sofre uma transformação profunda; segundo, uma atitude diferente em relação ao 'público' torna-se costumeira; terceiro, a produção artística tende a ser considerada como um tipo de produção especializada como tantas outras, sujeita às mesmas condições que a produção em geral; quarto, a teoria da realidade 'superior da arte', como colocação de uma verdade de imaginação, reveste-se de uma importância crescente; quinto, a representação do escritor como criador independente, como gênio autônomo, torna-se uma espécie de regra” (Williams apud Bourdieu, 1968, pp. 109-10).
\end{abstract}

A citação foi extraída do capítulo "O artista romântico", o mais propriamente sociológico de Cultura e sociedade, e sua importância na argumentação desenvolvida por Bourdieu pode ser dimensionada quando atentamos para o fato de que ele se vale da passagem para sustentar analiticamente a sua tentativa de reconstruir o processo histórico de autonomização do campo intelectual, latente em Williams e um problema fulcral, não apenas no texto em questão, mas em todo o esquema teórico de Bourdieu.

Tomando como referência o texto de Cultura e sociedade, chama a atenção o fato de Bourdieu ter citado uma passagem de capítulo aparentemente deslocado do argumento central do livro de Williams, estruturado primordialmente pela análise de um conjunto extenso de obras e pela reconstrução da tradição literária inglesa,

9. Cultura e sociedade é dividido em três partes - "Uma tradição do século XIX", "Interregno" e "Opiniões do século Xx" -, e esse capítulo é o segundo da primeira parte. 
que na perspectiva do autor nesse livro seria unificada pela crítica à sociedade industrial. Essa linhagem incluiria, além de escritores e escritoras ingleses nos séculos XIX e XX, críticos literários, para quem a cultura seria uma espécie de antídoto aos desajustes provocados pelo avanço do industrialismo. É justamente nessa direção que um analista como Paul Jones critica a leitura de Bourdieu por sua "incompreensão completa da relação entre esse capítulo e o livro como um todo" (2006, p. 201). Jones, contudo, desconsidera que a citação de Bourdieu pressupõe outra leitura possível de Cultura e sociedade, que toma esse capítulo como um dos eixos do livro, não apenas em função dos interesses de Bourdieu, mas também por sua função no desenvolvimento do argumento de Williams.

Mais precisamente, essa leitura sugeriria que o papel central desempenhado pelos escritores na crítica ao industrialismo na Inglaterra teria sido condicionado pela transformação das relações sociais de produção e circulação literárias que, segundo Williams, acompanharia a Revolução Industrial. Em decorrência da industrialização da produção de impressos, da ampliação do mercado literário, da formação de um público de classe média, da consolidação de uma nova concepção da arte (como "realidade superior") e do artista (como "gênio autônomo"), da profissionalização da atividade literária, portanto, os escritores ficariam legitimados como os porta-vozes da sociedade para refletir sobre as mudanças em curso e sobre a função da cultura nesse processo.

De qualquer forma, o desenvolvimento do projeto intelectual iniciado por Williams com esse livro reforça a pertinência da leitura de Bourdieu, uma vez que a abordagem sociológica seria aprofundada em The long revolution, livro que, não por acaso, suscitou críticas relembradas por Williams em $A$ politica e as letras nos seguintes termos:

Cultura e sociedade adquiriu rapidamente a reputação de ser um tipo de livro meritório e honroso, ao passo que The long revolution foi considerado escandaloso. Uma reclamação comum era a de que eu havia sido corrompido pela sociologia, que eu havia aderido à teoria (Williams, 2013, p. 128).

Na mesma direção da primeira citação (retirada de Cultura e sociedade), a passagem do livro The long revolution, reproduzida por Bourdieu pouco adiante no mesmo texto, sublinha as interpretações postuladas pelo autor galês sobre a literatura inglesa, desta vez a partir das propriedades sociais dos produtores culturais e do público. Novamente, faz sentido que Bourdieu citasse um extrato de The long revolution em "Campo intelectual e projeto criador", texto voltado à sistematização do "objeto" e dos "limites" da "sociologia da criação intelectual e artística" (Bourdieu, 
1968, p. 105). Vejamos o comentário de Bourdieu, seguido pela citação, incluídos em uma nota:

R. Williams esclarece também as relações de interdependência que unem o aparecimento de um novo público, que pertence a uma nova classe social, a um corpo de escritores saído da mesma classe e de instituições ou de formas artísticas criadas por esta classe. "O caráter da literatura foi visivelmente afetado pelo sistema de comunicação e pela mudança de público. Quando assistimos ao aparecimento de escritores de um novo grupo social, devemos considerar também as instituições e as formas criadas pelo conjunto do grupo a que pertencem. $\mathrm{O}$ teatro elisabetano [...], enquanto instituição, foi em grande parte criado por especuladores saídos das classes médias, vivendo de peças de escritores saídos em sua maioria de famílias de artesãos e de comerciantes, embora, de fato, tenha sido sempre combatido por essa classe média de comerciantes. Acolhendo um público popular, sobreviveu graças à proteção da corte e da nobreza [...]. Pode-se atribuir a formação de um público organizado de classes médias, no século XVIII, a certos escritores do mesmo grupo social, mas também, e sobretudo, pode-se ver nela o resultado de um desenvolvimento independente que ofereceu aos escritores sua oportunidade. A expansão e a organização desse público se prolongaram pelo século XIX, atraindo novos escritores de origens sociais diversas, mas homogeneizando-os através de suas instituições" (Williams apud Bourdieu, 1968, pp. 110-111).

A citação é mobilizada no passo em que Bourdieu associa o desenvolvimento do mercado cultural à constituição do campo e foi retirada do capítulo "A história social dos escritores ingleses" de The long revolution ${ }^{10}$, que discute em perspectiva de longa duração (1480-1930) o recrutamento social dos escritores, a partir de três parâmetros: origem familiar, formação educacional e atividade profissional. $\mathrm{O}$ trecho citado problematiza, especificamente, a transformação do recrutamento social dos produtores culturais e do público entre os séculos XVI e XIX. No século XVI, Williams se refere ao contexto do teatro elisabetano, que teria propiciado um certo grau de profissionalização dos escritores/dramaturgos. No entanto, esse impulso não teria efeito persistente, uma vez que o financiamento dessa instituição cultural ainda dependia do mecenato exercido pela nobreza, mesmo que os escritores e o público tivessem origem social média e popular. Na passagem do século XVIII ao XIX, a relação dos escritores de classe média com o público, também dessa classe, seria de outra ordem, porque viria a formar um mercado consumidor propriamente

10. O livro é dividido em três partes principais. Esse capítulo é o quinto da segunda parte, que reúne diversos textos de orientação sociológica e histórica mais explícita, como os que tratam do sistema educacional (capítulo 1 - "A educação e a sociedade britânica"), do "Crescimento do público leitor" (capítulo 2) e da imprensa popular (capítulo 3 - "O crescimento da imprensa popular"). 
dito, impulsionando de forma persistente a profissionalização dos escritores. Para Bourdieu, esse desenvolvimento do mercado condicionaria a autonomização do campo literário. Mais uma vez, portanto, Bourdieu fundamenta um passo decisivo de sua argumentação nos dados e na análise de Williams.

Vale notar que essa correlação entre o desenvolvimento do mercado e a autonomização do campo - mais especificamente, "os efeitos libertadores" provocados pelo mercado sobre os escritores - seria reforçada quase trinta anos depois em As regras da arte, de novo com uma menção a Williams:

A virtude maior dessa comparação [da passagem do servo de gleba ao trabalhador livre com a do escritor submetido ao mecenato ao escritor inserido no mercado] é prevenir contra a tendência muito difundida de reduzir esse processo fundamentalmente ambíguo apenas aos seus efeitos alienantes (na tradição dos românticos ingleses, analisada por Raymond Williams): esquece-se que ele exerce efeitos libertadores, por exemplo, oferecendo à nova "intelligentsia proletaroide" a possibilidade de viver, sem dúvida muito miseravelmente, de todos os pequenos ofícios ligados à literatura industrial e ao jornalismo, mas que as novas possibilidades assim adquiridas podem estar também no princípio de novas formas de dependência (Bourdieu, [1992] 2001, p. 72, grifos nossos).

Encontro

A participação de Williams em dezembro de 1976 no "Seminário de Sociologia da Cultura e dos Modos de Dominação”, dirigido por Bourdieu na École Normale Supérieure, e a consequente publicação do capítulo 12 de $O$ campo e a cidade na ARSS propiciaria um segundo contato, dessa vez presencial, entre os autores. Segundo documento consultado no arquivo de Raymond Williams - um cronograma das atividades programadas pelos anfitrióes franceses -, ele teria permanecido em Paris por uma semana, entre 9 e 16 de dezembro de 1976. Embora não seja possível depreender (com certeza) da programação as atividades que foram cumpridas, Williams teria oferecido uma espécie de minicurso sobre os romances de Thomas Hardy ${ }^{11}$ nos dias 10, 11, 13 e 14, uma aula aberta no dia 15 e uma fala no seminário de Bourdieu no dia 16.

O seminário e a revista representavam para Bourdieu, entre outros aspectos, meios para "lançar as bases e alianças com cientistas sociais estrangeiros considerados pares (Williams, Ginsburg, Schorske, Goffman etc.)” (Miceli, 2002), ainda

11. Provavelmente, o curso teria também como base o livro O campo e a cidade, cujo capítulo 18, "Wessex e a fronteira", trata de Hardy. 
quando o sociólogo francês não estava totalmente consagrado. A apresentação no seminário foi resenhada por Jean-Claude Chamboredon, como introdução ao texto na ARSS, e sugere que Williams discorreu sobre sua perspectiva analítica em geral e, especificamente, sobre $O$ campo e a cidade, que havia sido publicado na Inglaterra em 1973. Devemos notar que Chamboredon, no início e no final de seu pequeno texto sobre Williams ${ }^{12}$, destaca soluções analíticas de Williams que poderiam ser identificadas em Bourdieu:

A recusa da oposição corriqueira entre a história interna das obras e a história externa está na base da abordagem de Raymond Williams em seu livro sobre a evolução das imagens sociais

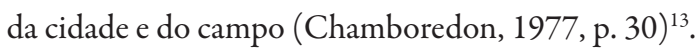

A história literária e a história das ideias conduzem, assim, a uma história do trabalho social de produção ideológica (Chamboredon, 1977, p. 31) $)^{14}$.

Vale notar que o livro de Wiliams e o capítulo publicado não propõem reflexões teóricas abstratas, mas sim uma análise sobre um problema concreto, o enraizamento histórico e social das imagens de campo e cidade incorporadas na literatura inglesa, tipo de abordagem afinada com a perspectiva de Bourdieu ${ }^{15}$ e reivindicada sistematicamente, com Chamboredon e Passeron, em Ofício de sociólogo (1968).

Anos mais tarde, Bourdieu faria uma menção direta e um breve comentário ao texto publicado na ARSS, no capítulo "Crítica da razão escolástica” do livro Meditaçôes pascalianas, editado na França em 1997 e no Brasil em 2001:

Tudo isso se manifesta muito bem na invenção, na Inglaterra do século XVII, do jardim natural, tal como analisa Raymond Williams: o novo arranjo constitui o campo inglês em paisagem sem camponeses, ou seja, num puro objeto de contemplação estética, fundado no culto do "natural" e na busca da linha sinuosa, inscrevendo-se na visão do mundo de uma burguesia

12. Segundo informação dada por Chamboredon em nota, a apresentação ao texto teria sido redigida a partir de suas anotações da comunicação de Williams.

13. No original em francês: "Le refus de l'opposition ordinaire entre l'histoire interne des oeuvres et le histoire externe est au principe de la démarche de Raymond Williams dans son livre sur l'evolution des images sociales de la ville et de la campagne".

14. No original em francês: "L'histoire littéraire et l'histoire des idées conduisent ainsi à une histoire du travail social de production idéologique".

15. Vale citar: "Na mesma medida em que me desagradam essas profissões de fé pretensiosas de pretendentes ávidos de sentar-se à mesa dos 'pais fundadores', deleito-me com essas obras em que a teoria, porque é como ar que se respira, está por toda parte e em parte alguma, no meandro de uma nota, no comentário de um texto antigo, na própria estrutura de um discurso interpretativo" (Bourdieu, 1996, p. 204). 
agrária esclarecida, que além de empreender uma transformação da exploração agrícola, pretende criar um universo visível totalmente desembaraçado de qualquer vestígio de trabalho produtivo e de qualquer referência aos produtores, a paisagem "natural” (Bourdieu, 2001, p. 35).

O comentário realizado em Meditações pascalianas por Bourdieu justamente sobre o texto publicado na ARSS vinte anos antes indicaria, ainda, a estratégia persistente de fortalecer uma rede internacional de autores, vinculados por uma perspectiva analítica compartilhada (Miceli, 2002). Vale notar que no capítulo III, "Os fundamentos históricos da razão", do mesmo livro, Bourdieu cita o artigo de Edward Thompson ${ }^{16}$ “Modos de dominação e revoluções na Inglaterra”, publicado em 1976 na ARSS, um ano antes do que o artigo de Williams.

No interior da argumentação de Bourdieu, a invenção social de uma "paisagem perfeita" seria exemplar para se apreenderem o processo de diferenciação dos campos de produção cultural e a gênese correlata de uma disposição estética pura. Ao mesmo tempo, a perspectiva de Williams seria um contraponto a qualquer exercício puramente filosófico e abstrato, servindo como argumento a favor de um estilo de reflexão sobre a cultura que, ao invés de denegar o social, iria ao encontro dele.

Vale notar ainda que a menção de Bourdieu a Williams em Meditaçõespascalianas se dá num livro com tom autobiográfico explícito, o que também caracteriza $O$ campo e a cidade. Sabe-se que o anexo ao primeiro capítulo de Meditaçóes seria incorporado ao posterior Esboço de autoanálise, mas todo o embate travado em Meditações com a filosofia envolve uma dimensão memorialística. No livro de Williams, esse enfoque orienta toda a argumentação, mas é possível notá-lo de modo mais direto na dedicatória aos avós camponeses paternos e maternos e no capítulo introdutório "Campo e cidade", no qual a lembrança de sua aldeia natal e a reconstituição da vida de seu pai são mobilizadas para embasar a confissão de que seu livro seria, também, um registro biográfico. Talvez com mais força ainda, mesmo que indiretamente, o capítulo "Wessex e a fronteira", sobre Thomas Hardy, justamente o autor que discutiu no minicurso oferecido em Paris, recupera sob o personagem principal de Jude the Obscure (1895) a própria experiência de Williams, tensionada entre sua origem camponesa e seu destino universitário:

Porém a questão é mais do que aprender termos e tons; é o que acontece conosco, o que realmente acontece conosco, quando tentamos atuar como mediadores desses mundos em

16. Sobre o contato anterior ao de Williams, entre Thompson e Bourdieu, ver a epígrafe deste artigo, que reproduz parte do conteúdo de um cartão-postal (sem data, mas provavelmente de 1975 ou 1976) enviado por Thompson a Williams, mencionando sua participação em um colóquio em Paris, no qual teria conhecido Bourdieu e ficado impressionado com ele e seu grupo. 
contraste: quando nos colocamos na posição de um Jude que teve permissão de entrar; ou quando voltamos para nosso lugar de origem, nossa família, e percebemos, em termos de ideia e de sentimento, o que significa a expressão "a volta do nativo". Isso tem uma importância especial para uma geração específica, de pessoas que vieram de famílias comuns, chegaram à universidade e têm de descobrir, durante toda uma existência, o que representa essa experiência (Williams, 1990, p. 271).

Essa tensão seria, também, um dos eixos principais do primeiro romance escrito por Williams, Border Country (1960), claramente autobiográfico, cujo enredo recupera a experiência de um jovem de origem camponesa na universidade e seu retorno à comunidade, movimentos que dão forma no livro à sensação de deslocamento produzida pela ascensão social do personagem, via formação educacional, entre o campo e a cidade. $\mathrm{O}$ estranhamento vivido pelo personagem no trânsito entre mundos distintos se expressa no romance pela oposição entre o apelido Harry e o nome oficial Matthew, pelos quais era reconhecido respectivamente na aldeia natal e na universidade, o que teria acontecido também com Raymond, chamado por seus familiares e amigos de Pandy, localidade do País de Gales em que nasceu, como Jim (Smith, 2008).

\section{Correspondência}

Um terceiro ponto de contato entre os dois autores seria a correspondência, da qual tivemos acesso, como já foi dito, às duas cartas remetidas por Bourdieu a Williams em 22 de dezembro de 1976 e 7 de setembro de 1977. A primeira foi enviada logo após a estadia de Williams em Paris, que terminou seis dias antes da redação da carta, e começa declarando a satisfação pelo encontro recente e a expectativa por um intercâmbio futuro persistente. Bourdieu menciona em seguida a leitura do texto "Developments in the sociology of culture" (Williams, 1976), que teria suscitado nele a impressão de um "encontro de mentes tão completo", referindo-se especificamente ao seu próprio artigo "Sociologues des mythologies et mythologie de sociologues" (Bourdieu e Passeron, 1963).

A leitura em paralelo dos dois textos mencionados, se não leva a nenhuma descoberta inusitada, permite especular com evidências mais concretas quais seriam as bases desse "encontro de mentes" postulado por Bourdieu. Todo o texto de Bourdieu e Passeron (1963) desenvolve uma crítica ácida aos intérpretes, Edgar Morin e outros (ironicamente nomeados como "profetas"), dos chamados "meios de comunicação de massa”, expressão que consideram problemática. Os autores refutam a noção de "massa”, em função de seu caráter preconceituoso e generalista, além de recusarem o modo de interpretação concentrado na circulação da suposta "cultura de massa" e 
quase nada interessado nos contextos e agentes envolvidos em sua produção ${ }^{17}$. Assim mesmo, a análise da circulação/recepção seria sociologicamente insuficiente por negligenciar a heterogeneidade social do público e sua capacidade de recepção crítica dos bens culturais consumidos. Em "Developments in the sociology of culture", essa mesma crítica à noção de massa aparece, embora sem a mesma centralidade no argumento geral do texto ${ }^{18}$. Mas talvez outro ponto que tenha chamado a atenção de Bourdieu (que não esclarece isso na carta) nesse texto de Williams tenha sido a sua defesa de uma abordagem atenta à "materialidade dos signos" (Williams, 1976, p. 505), ou seja, de uma perspectiva sociológica propriamente dita no exame das práticas culturais. Por fim, outro encontro possível entre os autores, suscitado pela leitura do texto de Williams em questão, talvez seja o entendimento da sociologia da cultura não apenas como uma especialidade, mas sobretudo como uma perspectiva de investigação capaz de perscrutar a lógica e os mecanismos de reprodução da sociedade capitalista.

Já sabemos que o texto de Williams publicado na ARSS foi um capítulo de $O$ campo e a cidade, mas a sequência da carta sugere que outra possibilidade havia sido aventada, a de publicar na revista uma parte do capítulo I de Televisão. Essa opção foi descartada, mas a negociação comprova que Bourdieu conhecia o livro de Williams ao escrever Sobre a televisão duas décadas mais tarde (1996), informação que não deve ser negligenciada numa possível comparação entre os dois livros. Vale destacar que o encontro entre os dois autores se deu no final de um período de grande produtividade por Williams, marcado pelas publicações de $O$ campo e a cidade (1973), Televisão (1974) e Marxismo e literatura (1977), todos envolvidos na relação direta entre os autores. Veremos que a segunda carta termina com uma menção ao último livro.

A segunda carta é uma resposta provável a uma missiva anterior de Williams (à qual ainda não tivemos acesso), na qual ele teria convidado Bourdieu a participar, como sugere a resposta, de uma obra coletiva intitulada Human communication, projeto que não teria prosseguido. Bourdieu aventa possibilidades de colaboração com os artigos "L'économie des échanges linguistiques" (1977a), "Le fétichisme de la langue" (1975) e partes dos livros $O$ amor pela arte (1969) e Un art moyen, essai sur les usages sociaux de la photographie (1965). Além dessas possíveis contribuições para pontos definidos por Williams, Bourdieu sugere a inclusão na obra do ponto "Linguagem e política".

17. Bourdieu e Passeron valorizam, em contraponto, análises sociológicas sobre práticas culturais que relacionem as instâncias de produção e as de circulação/recepção, o que também é reivindicado por Raymond Williams em "Developments in the sociology of culture" (1976).

18. Vale notar, entretanto, que Williams deu muita importância a essa questão na conclusão de Cultura e sociedade. 
A carta, então, termina com uma menção à Marxismo e literatura e ao "acordo miraculoso":

Eu devia ter começado dizendo-lhe que li seu livro Marxismo e literatura com grande interesse e concordo profundamente com você. (Você provavelmente viu a extensão de nosso acordo em meu texto sobre a linguagem. O fato é que me sinto tão isolado aqui que a extensão de nosso acordo me parece de certo modo miraculosa) (Carta de Bourdieu a Williams de 7 de setembro de 1977) $)^{19}$.

Talvez o acordo postulado por Bourdieu possa ser resumido, em termos teóricos, em dois pontos principais. O primeiro se daria pela reivindicação por ambos de uma concepção materialista da cultura, cujo pressuposto mais geral seria seu entendimento como prática social, posição assumida por Williams no texto "Base e superestrutura na teoria da cultura marxista” (1973), artigo que sintetiza Marxismo e literatura:

Agora, se voltarmos à questão cultural na sua forma mais usual - quais são as relações entre arte e sociedade, ou entre literatura e sociedade? - à luz da discussão anterior, temos de dizer, em primeiro lugar, que não há relações entre literatura e sociedade nessa forma abstrata. A literatura apresenta-se, desde o início, como uma prática na sociedade. (Williams, 2011, p. 61).

O segundo se refere, como sugerido acima, à concepção mais geral de ambos sobre o estatuto teórico e empírico da sociologia da cultura. A dimensão cultural estaria em pé de igualdade (e imbricada) com a economia e a política e mereceria uma atenção tão grande como a dedicada usualmente pelos historiadores e cientistas sociais a essas outras esferas da realidade. Nesse sentido, a sociologia da cultura teria a ambição macrossociológica de compreender a dinâmica social em sua totalidade, não constituindo assim uma área disciplinar específica, mas uma perspectiva de análise abrangente, e livros como The long revolution e $A$ distinção comprovam isso pelo alcance das interpretações que sugerem.

Mas o "milagre" postulado por Bourdieu pode ser relacionado, também, à similitude entre as trajetórias dos dois autores, não aventada explicitamente por Bourdieu em seu comentário na carta, mas que presumimos que tenha condicionado a afinidade teórica entre ambos. Os dois tiveram origem pequeno-burguesa ou popular, além

19. No original em inglês: "I should have begun by telling you that I read your book Marxism and Literature with enormous interest and agree profoundly with you. (You have probably seen the extent of our agreement in my text on language. The fact is, I feel so isolated here that the extent of our agreement seems to me somewhat miraculous)" (Richard Burton Archives - Swansea University. Referência: WWE/2/1/16/33). 
de provinciana. Tanto Williams como Bourdieu ascenderam socialmente pela via educacional e teriam que enfrentar experiências de desenraizamento e reconversão social no curso e ao cabo de percursos escolares bem-sucedidos, culminando nas mais importantes instituições de ensino superior da Inglaterra e da França. Nesse sentido, é muito significativa e talvez não casual a qualificação por Bourdieu do acordo teórico como "miraculoso", já que as duas trajetórias seriam, tipicamente, as dos "oblatos miraculosos" ${ }^{20}$, mencionados pelo sociólogo francês, que conseguiriam a duras penas romper barreiras para escalar o sistema educacional, apesar da naturalização posterior desses feitos que viria a reboque da consagração.

Williams nasceu em 1921, já vimos, no pequeno vilarejo de Pandy, na fronteira do País de Gales com a Inglaterra, sendo filho único, como Bourdieu ${ }^{21}$, de um pai funcionário da estrada de ferro da região e de uma mãe oriunda de uma família de camponeses, ambos militantes do Partido Trabalhista. Sua origem familiar é narrada em $A$ politica e as letras e, também, em $O$ campo e a cidade que, como dissemos, apresenta um eixo autobiográfico:

Quando nasci, meu pai era sinaleiro, na cabine do vale; integrava uma rede que se estendia a lugares conhecidos, Newport e Hereford, mais ao longe Londres; ele, porém, continuava um aldeão, com seus jardins e suas abelhas, levando frutas e legumes ao mercado, de bicicleta [...]. Como seu pai ele nascera para aquela terra, porém - como seu pai - não podia viver dela (Williams, 1990, p. 15).

Iniciando uma carreira escolar convencional na escola primária de sua aldeia natal, na qual "a educação era vista como o escape da condição de um emprego frustrante" (Williams, 2013, p. 14), Williams conseguiria ingressar em uma grammar school e, após o exame para obter o Higher School Certificate, ser indicado para ingressar em Cambridge. Dois aspectos sobre a sua passagem pela universidade devem ser ressaltados: primeiro, sua entrada no prestigioso curso de inglês, onde a crítica literária era praticada e entendida como disciplina dominante no interior das humanidades; segundo, a adesão de primeira hora ao Clube Socialista de Cambridge e a filiação imediatamente posterior ao Partido Comunista da Grã-Bretanha. O peso maior da

20. Vale citar: "Não posso retomar aqui toda maquinaria do processo de consagração que, desde o concurso de admissão à classe preparatória até o concurso de ingresso na Escola Normal, conduz os eleitos (em especial, os oblatos miraculosos) a eleger a Escola que os elegeu, a reconhecer os critérios de eleição que os constituíram elite; bem como, na sequência, a orientá-los, sem dúvida com tanto mais empenho quanto maior o grau de louvação, em direção à disciplina-rainha” (Bourdieu, 2005, p. 41).

21. Poderíamos qualificar as famílias de ambos como "pequeno-burguesas", que, segundo o próprio Bourdieu em $A$ distinção, restringem o número de filhos para investir o máximo do pouco recurso disponível na obtenção de capital cultural, como meio de ascender socialmente? 
militância política, apesar das dúvidas e descontinuidades, em sua trajetória, aliás, marcaria uma diferença em relação ao percurso de Bourdieu, também afetado pela política (seu pai também foi militante de esquerda), mas em menor grau e mais tardiamente.

O projeto intelectual de Williams seria reorientado desde Cultura e sociedade por uma dissensão em relação à crítica literária acadêmica ${ }^{22}$, tanto pelo viés marxista de seus escritos como pela adoção de uma perspectiva sociológica cada vez mais pronunciada $^{23}$. Sua carreira acadêmica se concretizaria com o convite para lecionar em Cambridge no início da década de 1960. A frase de Bourdieu sobre sua própria trajetória, ao referir-se à "amplitude de meu percurso no espaço social e da incompatibilidade prática entre os mundos sociais que tal percurso conecta sem de fato reconciliá-los" (Bourdieu, 2005, p. 37), no início do Esboço de autoanálise, se ajusta quase perfeitamente, portanto, ao itinerário de Williams.

Como Williams, Bourdieu alcançou no ensino superior uma instituição do topo do sistema educacional de seu país, a École Normal Supérieure, e se formou na disciplina dominante das humanidades, nesse caso, a filosofia, da qual se afastaria progressivamente a favor da sociologia, por ele defendida em toda sua carreira e afirmada em oposição a figuras emblemáticas do campo intelectual francês do meio século Xx, como Sartre e Lévi-Strauss. Talvez essa atitude de confrontação em relação às disciplinas de origem possa ser relacionada às origens sociais populares de ambos. Como se sabe, Bourdieu nasceu em um vilarejo na região do Bearn e proveio, por parte do pai, carteiro de profissão, de uma família camponesa modesta e, por parte de mãe, de uma família camponesa remediada. Tais pontos de partida os constituíram como outsiders, cronicamente desajustados ao meio universitário de elite.

Se a origem social desfavorável condicionou as dissensões de Williams e Bourdieu nos campos intelectuais em que se afirmaram, mais especificamente em relação às disciplinas de formação, crítica literária e filosofia, respectivamente, a experiência da guerra teria, possivelmente, amplificado o desconforto subjetivo de ambos no interior das instituições educacionais de elite e catalisado o enfrentamento com as tradições dominantes e as inovações daí decorrentes. Williams combateu na Segunda Guerra, comandando um batalhão de tanques, enquanto Bourdieu cumpriu o serviço militar em plena Guerra de libertação da Argélia. De qualquer forma, ambos teriam que enfrentar durante toda a vida os efeitos do desenraizamento. No caso de Williams, ele teria sido menos exposto ao dilaceramento, se acreditarmos em suas manifestações explícitas a respeito em A política e as letras. Talvez o engajamento

22. Sobretudo a que foi encarnada por F. R. Leavis e pelo grupo da revista Scrutiny.

23. Para uma reconstrução teórica da perspectiva analítica de Raymond Williams e sua relação com o marxismo inglês, ver Rivetti (2015). 
político tenha arrefecido o desencaixe provocado pelo seu deslocamento no espaço social. A aposta convicta de Bourdieu por uma militância científica (a partir da qual desembocaria tardiamente na política), se conduziu a uma abordagem sociológica inovadora e mesmo a uma "revolução simbólica", não teria amenizado seu sofrimento:

E tudo o que disse aqui a respeito das causas ou das razões de cada uma das experiências evocadas, como minhas aventuras argelinas ou meus entusiasmos científicos, mascara, portanto, a pulsão subterrânea e a intenção secreta que constituíam a face oculta de uma vida dilacerada (Bourdieu, 2005, p. 98).

\section{Análise}

O último contato principal entre os autores seria um texto alentado de apresentação às traduções de dois excertos de $A$ distinção: crítica social do julgamento $(1979)^{24}$, além do artigo "La production de la croyance: contribuition à une économie des biens symboliques" (Bourdieu, 1977b) ${ }^{25}$, publicadas na revista Media, Culture \& Society (n. 2, 1980). "Pierre Bourdieu and the sociology of culture: an introduccion" (1980) foi redigido por Raymond Williams em parceria com Nicholas Garnham, que organizou esse número do periódico (Garnham e Williams, 1980).

Vale notar que antes do texto de apresentação, no "Editorial" desse segundo número da revista, provavelmente redigido por Garnham, os editores reconhecem uma dívida com "Bourdieu e seus colegas do Centro de Sociologia Europeia" (Editorial, 1980, p. 207) e apresentam o número, também, como uma contrapartida diplomática às iniciativas editoriais anteriores de Bourdieu a favor de Williams e de autores próximos a ele:

Eles foram responsáveis por introduzir The uses of literacy a um público francês e publicaram em sua revista Actes de la Recherche en Sciences Sociales trabalhos de Williams, Thompson, Hobsbawm e Willis. Este número é, em parte, uma tentativa de construir reciprocamente sobre esses vínculos estabelecidos (Editorial, 1980, p. 208) ${ }^{26}$.

24. Foram publicados uma seção da primeira parte, "Títulos de nobreza cultural" (17-61), na edição brasileira, e o quadro (116-121), que contém os gráficos 5 e 6, da segunda parte.

25. Originalmente publicado na ARSS, vol. 13, 1977.

26. No original em inglês: "They were responsible for introducing The Uses of Literacy to a French readership and have published in their journal Actes de la Recherche en Sciences Sociales work by Williams, Thompson, Hobsbawm and Willis. This issue is in part an attempt to build reciprocally on those existing links". 
Williams e Garnham iniciam o texto de apresentação lembrando que a recepção de Bourdieu na Grã-Bretanha (e nos Estados Unidos) seria ainda fragmentária, em 1980, e que o alcance de sua obra não havia sido até então devidamente estimado nos dois contextos ${ }^{27}$. Os autores destacam a abrangência da obra de Bourdieu, tanto em função do leque variado de objetos analisados, como pelo eixo comum de seus trabalhos, todos de alguma forma voltados ao problema da "reprodução". Por isso mesmo, embora concentrados na análise da Distinção, visavam a introduzir a "estrutura do pensamento de Bourdieu” (Garnham e Williams, 1980, p. 209), interessados nos possíveis aportes dessa perspectiva aos estudos culturais e de mídia ingleses, então às voltas com disputas entre perspectivas de análise do problema da ideologia mais abstratas (inspiradas em Althusser) e vertentes que reivindicavam abordagens históricas e sociológicas sobre o mesmo problema, enfatizando as determinações de classe.

Segundo os autores, a solução dada por Bourdieu em sua "teoria da ideologia ou do poder simbólico" (Idem, p. 210) permitiria superar tal impasse analítico, combinando determinações econômicas e de classe mais gerais aos condicionantes específicos do campo intelectual no exame da gênese das práticas e representações simbólicas.

O tom extremamente elogioso do texto pode ser estimado pela qualificação da sociologia de Bourdieu como materialista, diretamente interessada em desvendar os mecanismos de dominação e de reprodução das desigualdades econômica e cultural, sem negligenciar a especificidade dessa dimensão (cultural) da realidade social. Mas o elogio atinge seu ápice ao atribuir ao pensamento de Bourdieu uma dimensão crítica, que o aproximaria de Marx:

O segundo vínculo importante entre a obra de Bourdieu e a tradição central do materialismo histórico é de que ela é moldada na forma de uma "crítica" no sentido clássico praticado pelo próprio Marx. Isso significa que não se pode cometer o erro de adaptar a análise teórica e empírica de Bourdieu do poder simbólico a quaisquer subdisciplinas marginais tais como os estudos culturais ou a sociologia da cultura e do conhecimento. Essa análise reside no coração mesmo de sua teoria geral mais ampla, assim como as teorias do fetichismo e da ideologia na obra de Marx, posto que ela oferece as condições mesmas de sua própria cientificidade potencial (Idem, p. 211)

27. Nos Estados Unidos A distinção foi traduzida em 1984 e esse seria um marco importante da recepção mais favorável e generalizada da obra de Bourdieu nesse país.

28. No original em inglês: "The second important link between Bourdieu’s work and the central tradition of historical materialism is that it is caste in the form a 'critique' in the classical sense practiced by Marx himself. That is to say one must not make the mistake of appropriating Bourdieu's theoretical and empirical analysis of symbolic power to some marginal sub-disciplines such as cultural studies or 
Deve-se notar que o elogio, pelo paralelo com Marx, foi enunciado ainda quando Bourdieu não havia se consagrado plenamente na França e apenas de maneira incipiente no espaço anglo-saxão $0^{29}$. Ao mesmo tempo, a tentativa de associar Bourdieu a Marx reforçaria a legitimidade da obra do autor alemão e da tradição a ela filiada, especialmente a vertente heterodoxa que Williams defendia na Inglaterra. No restante do texto, os autores reconstroem a teoria da prática de Bourdieu e o núcleo da argumentação desenvolvida na Distinção por meio de uma leitura de certo modo enviesada, especialmente interessada nas determinações de classe na conformação do habitus, nos mecanismos de dominação inscritos na hierarquização dos padrões de consumo e de gosto, implicados na distinção entre as classes e, também, no exame dos condicionamentos gerais e específicos das práticas artísticas e culturais, envolvidas, mesmo que de forma mediada, na produção das relações de dominação entre as classes e frações de classe.

O texto é concluído com a reafirmação do "materialismo" ${ }^{30}$ do pensamento de Bourdieu e de sua potência analítica, em função da centralidade por ele atribuída à luta de classes (nas dimensões social e simbólica), da valorização da cultura da classe trabalhadora e da percepção das contradições entre a realidade social objetiva e as formas de consciência, atribuídas pelos autores como elementos da interpretação de Bourdieu. Segundo Garnham e Williams, tal interpretação permitiria aventar alternativas de prática política. Como se sabe, entretanto, Bourdieu não propôs em $A$ distinção uma saída política a partir de sua análise e essa seria, segundo os intérpretes, a limitação de seu pensamento, "um resíduo funcionalista/determinista" (Idem, p. 222):

No entanto, é preciso assinalar que, diferentemente de muitos que criticariam essa posição, ele é (a) resolutamente comprometido com uma teoria materialista da luta de classes e da posição da luta simbólica no interior desse conflito mais amplo; (b) especialmente em $A$ distinção ele exibe um atributo bastante raro na esquerda, isto é, uma avaliação positiva e não condescendente dos valores e aspirações culturais da classe trabalhadora que, ao mesmo tempo, nunca recai em um populismo ou obreirismo inocentes; (c) que sua teoria, ainda que concentrada no problema do poder simbólico, torna completamente possível a análise concreta de contradições específicas entre as condições sociais objetivas determinadas pelo

the sociology of culture and knowledge. This analysis lies at the very heart of his wider general theory, just as theories of fetishization and ideology do in Marx work, because it provides the very conditions of its own potential scientificity".

29. Bourdieu não havia ainda, por exemplo, ingressado no Collège de France, o que ocorreu em 1981.

30. O "materialismo" diria respeito, sobretudo, ao pressuposto comum a Williams e Bourdieu de que a cultura seria uma prática social. Além disso, a qualificação por Garnham e Williams da sociologia de Bourdieu como materialista visava a aproximá-la, de modo geral, ao marxismo e, em especial, à posição de Williams em seu interior. 
modo de produção e a consciência e as práticas de classes e de frações de classes. Contradições que podem oferecer a possibilidade concreta para mobilização e ação revolucionárias. Contudo, é preciso dizer que nos parece (e essa é em grande medida uma questão de tom, nuance e atitude) ser esse um resíduo funcionalista/determinista no conceito de reprodução de Bourdieu que o leva a colocar menos ênfase nas possibilidades de mudança real e inovação que a sua teoria ou sua pesquisa empírica tornam necessária (Idem, p. 222) ${ }^{31}$.

Para concluir, se não é o caso aqui de avaliar se a leitura de Williams e Garnham é pertinente ou não, devemos realçar o componente político desse movimento intelectual de aproximação dos dois autores e, em particular, de Williams, a Bourdieu. Sugerimos que a relação mais direta entre ciência e política no projeto intelectual de Williams estaria por trás desse modo de se apropriar do pensamento de Bourdieu, que lhe serviria de "aliado" em seu contexto de origem nas disputas internas ao campo marxista inglês. Do outro lado, vimos no início deste artigo que as incorporações de Williams por Bourdieu, desde as citações em "Campo intelectual e projeto criador" (Bourdieu, 1968), atenderam a um propósito predominantemente científico, o de reforçar a construção de um esquema teórico e interpretativo voltado ao problema da autonomização dos campos de produção cultural. Além disso, por meio do convite para o seminário de Paris e para publicar na ARSS, visava a estabelecer uma parceria estratégica no espaço sociológico transnacional.

31. No original em inglês: "However it has to be stated that unlike many who would criticize this position he is (a) resolutely committed to a materialist theory of class struggle and of the position of symbolic struggle within that wider struggle (b) especially in La distinction he exhibits a very rare attribute on the left, namely a positive and unpatronizing valuation of the cultural values and aspirations of the working class which at the same time never lapses into naive populism or workerism (c) that his theory, while focused on the problem of Symbolic power, allows fully for the concrete analysis of the specific contradictions between the objective social conditions determined by the mode of production and the consciousness and practices of classes and class fractions, contradictions that might offer the concrete possibility of revolutionary mobilization and action. However it has to be said that there seems to us (and this is very much a question of tone, nuance and attitude) to be a functionalist/determinist residue in Bourdieu's concept of reproduction which leads him to place less emphasis on the possibilities of real change and innovation than either his theory or his empirical research makes necessary". 
Referências bibliográficas

Bortoluci, José Henrique; Jackson, Luiz Carlos \& Pinheiro Filho, Fernando A. (2015),

"Contemporâneo clássico: a recepção de Pierre Bourdieu no Brasil”. Lua Nova, 94: 217-254.

Bourdieu, Pierre. (1968), “Campo intelectual e projeto criador”. In: Pouillon, Jean et al. (orgs.). Problemas do estruturalismo. Rio de Janeiro, Zahar, pp. 105-145.

Bourdieu, Pierre. (1970), La reproduction: élements pour une théorie du système d'enseignement. Paris, Minuit. Ed. bras.: (1992), A reprodução: elementos para uma teoria do sistema de ensino. Tradução de Reynaldo Bairão. Rio de Janeiro, Francisco Alves.

Bourdieu, Pierre. ([1974] 2011), A economia das trocas simbólicas. 7 ed. Introdução, organização e seleção de Sergio Miceli. São Paulo, Perspectiva.

Bourdieu, Pierre. (22 dez. 1976; 7 set. 1977; 8 abr. 1987), Cartas a Raymond Williams. Disponíveis no Richard Burton Archives, Swansea University, País de Gales.

Bourdieu, Pierre. (1977a), "L'économie des échanges linguistiques". Langue Française, 34: 17-34. Disponível em https://www.persee.fr/doc/lfr_0023-8368_1977_num_34_1_4815. Ed. bras.: Bourdieu, Pierre. (1996), A economia das trocas linguisticas: o que falar quer dizer. Tradução de Sergio Miceli. São Paulo, Edusp.

Bourdieu, Pierre. (1977b), "La production de la croyance: contribution à une économie des biens symboliques". Actes de la Recherche en Sciences Sociales, 13: 3-43. Disponível em https://www.persee.fr/doc/arss_0335-5322_1977_num_13_1_3493.

Bourdieu, Pierre. (1979), La distinction: critique sociale du jugement. Paris, Minuit. Ed. bras.: (2008), A distinção: crítica social do julgamento. Tradução de Daniela Kern e Guilherme J. F. Teixeira. São Paulo/Porto Alegre, Edusp/Zouk.

Bourdieu, Pierre. ([1992] 2001), As regras da arte: gênese e estrutura do campo literário. São Paulo, Companhia das Letras.

Bourdieu, Pierre. ([1996] 1997), Sobre a televisão. Rio de Janeiro, Jorge Zahar

Bourdieu, Pierre. ([1997] (2001), Meditaçôes pascalianas. Rio de Janeiro, Bertrand Brasil.

Bourdieu, Pierre. (2005), Esboço de autoanálise. São Paulo, Companhia das Letras.

Bourdieu, Pierre \& Passeron, Jean-Claude. (décembre 1963), "Sociologues des mythologies et mythologies des sociologues". Les Temps Modernes, Paris, 19 (211): 998-1021.

Bourdieu, Pierre; Boltanski, L. \& Castel, R. (1965), Un art moyen: essai sur les usages sociaux de la photographie. Paris, Minuit.

Bourdieu, Pierre; Chamboredon, Jean-Claude \& Passeron, Jean-Claude. ([1968] 2007), Ofício de sociólogo: metodologia da pesquisa na sociologia. Petrópolis, Vozes.

Bourdieu; Pierre \& Darbel, Alain. ([1969] 2011), L'amour de l'art: les musées d'art européens et leur public. Paris, Minuit. Ed. bras.: (2007), O amor pela arte: os museus de arte na Europa e seu público. 2 ed. Tradução de Guilherme João de Freitas Teixeira. São Paulo/ Porto Alegre, Edusp/Zouk. 
Bourdieu, Pierre \& Boltanski, Luc (1975), "Le fétichisme de la langue”. Actes de la Recherche en Sciences Sociales. 1 (4): 2-32. Disponível em https://www.persee.fr/doc/arss_03355322_1975_num_1_4_3417.

Chamboredon, Jean-Claude. (1977), "Raymond Williams. Plaisantes perspectives”. Actes de la Recherche en Sciences Sociales, 17-18: 29-36.

EdtTorial (1980), Media, Culture \& Society, 2 (3): 207-208.

Garnham, Nicholas \& Williams, Raymond. (1980), "Pierre Bourdieu and the sociology of culture: an introduction”. Media, Culture \& Society, 2 (3): 209-223.

Hardy, Thomas. ([1895] 2019), Jude the Obscure. Londres, Penguin Books. Ed. bras.: (1958), Judas o obscuro, romance. Tradução de Octavio de Faria. Belo Horizonte, Itatiaia.

JoNEs, Paul. (2006), Raymond Williams's sociology of culture: a critical reconstruction. Londres, Palgrave/Macmillan.

Miceli, Sergio. (2002), “Uma revolução simbólica”. Folha de S.Paulo, São Paulo, p. A3, 27/1.

Miceli, Sergio. (2005), “Pierre Bourdieu: Cronologia de vida e obra”. In: Bourdieu, Pierre. Esboço de autoanálise. São Paulo, Companhia das Letras, pp. 137-140.

Passiani, Enio. (2009), "Afinidades seletivas: uma comparação entre as sociologias da literatura de Pierre Bourdieu e Raymond Williams”. Estudos de Sociologia, Araraquara, 14 (27): 285-299.

PInto, Louis. (2000), Pierre Bourdieu e a teoria do mundo social. Rio de Janeiro, FGV.

Rivetti, Ugo Urbano Casares. (2015), Crítica e modernidade em Raymond Williams. São Paulo, dissertação de mestrado, Faculdade de Filosofia, Letras e Ciências Humanas da Universidade de São Paulo.

SchüCkıng, Levin Ludwig. (1950), El gusto literario. Tradução de M. F. Alatorre. México/ Buenos Aires, Fondo de Cultura Económica (Breviários del FCE, 24).

Smith, Dai. (2008), Raymond Williams: a warrior's tale. Cardigan, Parthian.

Thompson, E. P. ([ $\left.{ }^{*} 1975\right]$ s.d.), Cartão-postal a Raymond Williams. Fonte: Richard Burton Archives - Swansea University. Referência: WwE/2/1/16/365.

Thompson, E. P. ([1976] 2001), "Modos de dominação e revoluções na Inglaterra”. In: As peculiaridades dos ingleses e outros artigos. São Paulo, Unicamp, pp. 203-225.

Williams, Raymond. (1958), Culture and Society: 1780-1950. Nova York, Columbia University Press. Ed. bras. (1969): Cultura e sociedade: 1780-1950. São Paulo, Companhia Editora Nacional.

Williams, Raymond. ([1960] 2017), Border country. Cardigan, Parthian.

Williams, Raymond. (1961), The long revolution. Londres, Chatto \& Windus.

Williams, Raymond. (1974), Television: technology and cultural form. Londres, Fontana/Collins. Williams, Raymond. (1976), “Developments in the sociology of culture”. Sociology, 10 (3): 497-506.

Williams, Raymond. ([1977] 1979), Marxism and literature. Londres, Oxford University Press. Ed. bras.: Marxismo e literatura. Tradução de Waltensir Dutra. Rio de Janeiro, Zahar. 
Williams, Raymond. ([1973] 1990), O campo e a cidade: na história e na literatura. São Paulo, Companhia das Letras.

Williams, Raymond. (1992), Cultura. Tradução de Lólio Lourenço de Oliveira. Rio de Janeiro, Paz e Terra.

Williams, Raymond. (2011), "Base e superestrutura na teoria da cultura marxista”. In: WILLIAMS, Raymond. Cultura e materialismo. São Paulo, Editora Unesp, pp. 43-68.

Williams, Raymond. (2013), A politica e as letras: entrevistas da New Left Review. São Paulo, Editora Unesp.

\section{Resumo}

Pierre Bourdieu e Raymond Williams: correspondência, encontro e referências cruzadas

A breve e concentrada correspondência entre Raymond Williams (1921-1988) e Pierre Bourdieu (1930-2002) comprova a existência de relações concretas, de mão dupla, entre os autores galês e francês, muito sugestivas para se pensar o desenvolvimento da sociologia da cultura europeia na segunda metade do século xx. O objetivo principal deste texto é recensear os contatos que eles mantiveram, além da correspondência, por meio de citações cruzadas, de um seminário em Paris no ano de 1976 e de um texto crítico de Williams em parceria com Nicholas Garnham, publicado em 1980, sobre a obra de Bourdieu, em seguida à publicação de $A$ distinção na França. Palavras-chave: Pierre Bourdieu; Raymond Williams; Correspondência; Citações; Sociologia da cultura.

\section{Abstract}

Pierre Bourdieu and Raymond Williams: correspondence, meeting and cross references

The short and enclosed correspondence between Raymond Williams (1921-1988) and Pierre Bourdieu (1930-2002) proves the existence of actual and mutual relations between the Welsh and the French authors, very worthy in order to reflect on the development of the European Sociology of culture during the second half of the twentieth century. The main purpose of this article is to recover the contacts they kept, apart from the correspondence, through crossed citations, a seminar in Paris in 1976 and a critical text by Williams in partnership with Nicholas Garnham, published in 1980, on the work of Bourdieu after the printing of La Distinction in France. Keywords: Pierre Bourdieu; Raymond Williams; Correspondence; Quotations, Sociology of culture. 
Pierre Bourdieu e Raymond Williams: correspondência, encontro e referências cruzadas, pp. 183-204

Texto recebido em 11/12/2019 e aprovado em 3/3/2020.

DOI: 10.11606/0103-2070.ts.2020.164991.

Luiz Carlos Jackson é professor do Departamento de Sociologia da Universidade de São Paulo.E-mail: ljackson@usp.br.

Ugo Rivetti é doutorando no Programa de Pós-graduação em Sociologia da Universidade de São Paulo (bolsista Capes). E-mail: uc.rivetti@gmail.com.

(c) 